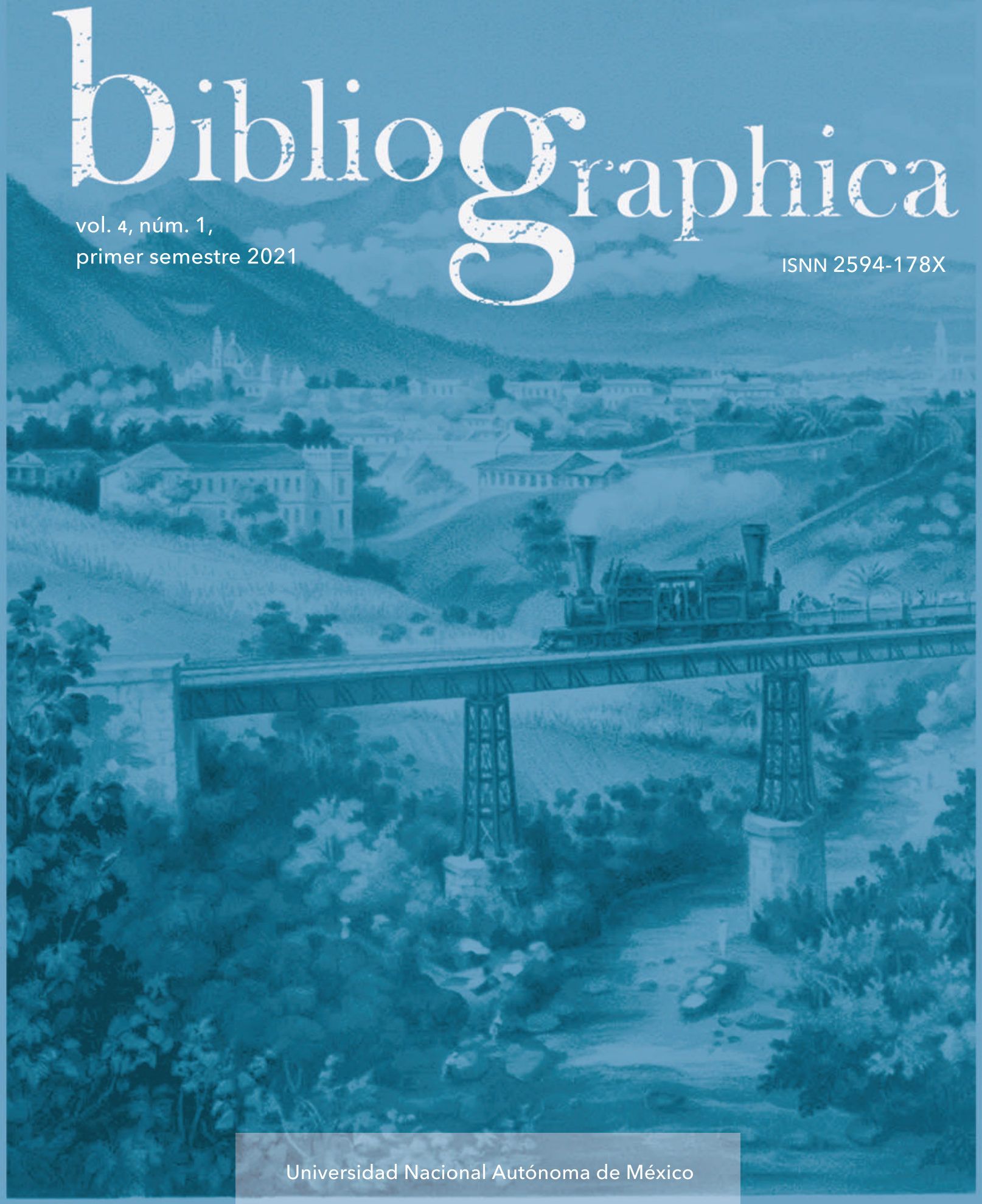




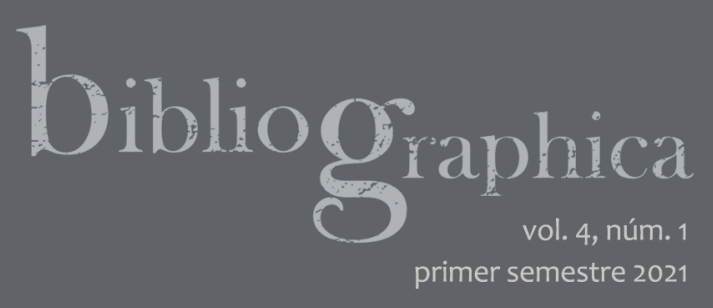

\title{
Aproximación a la historia literaria del derecho de autor en la edición chilena de libros, 1776-1900
}

\author{
An Approach to the Literary History \\ of Author's Right in the Chilean \\ Edition of Books, 1776-1900
}

\section{Eduardo Farías Ascencio}

Universidad Diego Portales,

Facultad de Comunicación y Letras,

Santiago de Chile. Chile

eduardo.farias.ascencio@gmail.com

http://orcid.org/0000-0002-4706-1375

Recepción: 21.09.2020 / Aceptación: 25.11.2020

DOI: https://doi.org/10.22201/iib.2594178xe.2021.1.92 
Resumen

Palabras clave

Abstract

Keywords
Esta investigación ahonda en la historia literaria del derecho de autor en la edición de libros en Chile, durante un primer periodo (entre 1776 y 1900), historia que se nos muestra en el peritexto editorial sobre derecho de autor que aparece actualmente en la hoja legal. Los objetivos son hallar el primer peritexto editorial sobre derecho de autor en la edición chilena de libros y abstraer los modelos literarios usados en esos peritextos editoriales, junto con su desarrollo histórico. El artículo aporta una mirada a una historia literaria alternativa a la de la literatura, una historia literaria de editores, escrita en los peritextos editoriales de dicha normativa. La relevancia radica en la investigación sobre esta otra historia literaria y en su complejidad. En la historia del libro en Chile, el peritexto editorial de derecho de autor tiene los antecedentes de la licencia católica de impresión y la licencia estatal de impresión.

Derecho de autor; derecho de reproducción; paratexto editorial; peritexto editorial; edición de libros; edición chilena; historia editorial.

This investigation delves into the literary history of copyright in the publishing of books in Chile, during a first period (between 1776 and 1900), a history that is shown in the editorial peritext on author's right that appears on the copyright page. The objectives are to find the first editorial peritext on author's right in the Chilean edition of books, and to abstract the literary models used in those editorial peritexts, along with their historical development. This article provides a look at an alternative literary history to that of literature, a literary history of editors, written in the editorial peritexts on author's right. The relevance lies in the research of this other literary history and its complexity. In the history of books in Chile, the editorial peritext on author's right has its background in the Catholic printing license and the State's printing license.

Copyright; reproduction right; editorial paratext; editorial peritext on author's right; book publishing; Chilean edition; editorial history. 


\section{Introducción}

Es evidente que el papel del derecho de autor radica en la regulación legal que realiza del negocio del libro cuando protege desde la creación una obra, sea o no literaria. Como sabemos, en Chile usualmente el derecho de autor coexiste con el copyright, el que se simboliza con (C) y determina, junto con el derecho de autor, la relación económica y legal de autores con agentes literarios, de autores con editores, de los editores con el público lector, periodistas, agentes literarios, con otros editores, en la producción y en la compra/venta del objeto libro. Sin embargo, el derecho de autor no siempre ha existido como tal, tiene una historia pasada y un presente en el cual compite con alternativas no reconocidas legalmente, alternativas que posibilitan lógicas distintas al monopolio del contenido de los derechos reservados.

Es relevante señalar que el derecho de autor no se reduce únicamente a la esfera del libro, sino que también se relaciona con otros diversos conceptos. En cuanto al ecosistema del libro en Chile, el derecho de autor está ligado al desarrollo de los conceptos: autor, obra, creación humana, creación intelectual derecho de autor, cesión de derechos, propiedad intelectual, contrato de cesión y peritexto editorial de derecho de autor, por ejemplo.

La presente investigación trata de construir una aproximación a la historia literaria del derecho de autor en la historia chilena del libro, desde 1776 hasta 1900, mediante el análisis del peritexto editorial de derecho de autor, un paratexto presente en las ediciones de los libros con un carácter marcadamente ideológico, político, respecto de los límites en el uso del libro y de la propiedad intelectual sobre la obra, texto que actualmente no es creación del autor sino del editor, texto que ha tenido una evolución desde finales del siglo XVIII en el territorio chileno.

Esta investigación no solamente posee un enfoque histórico, sino también literario, porque se torna evidente que el peritexto editorial de derecho de autor, al mirar su registro en distintas ediciones, es un texto con una evolución rastreable y porque es posible encontrar creatividad literaria en su construcción escrita; es factible afirmar que el peritexto de derecho de autor puede ser un texto literario, distinto al ya contenido en el libro. ${ }^{1}$ Por tanto, en la historia

${ }^{1}$ El germen de esta investigación en curso comenzó con la autoedición del libro Dere-
chos (Gramaje Ediciones, 2018), en el que reuní frases de copyright de ediciones chilenas,
españolas, mexicanas, peruanas y brasileñas, junto con las referentes a las alternativas al
copyright. En aquel primer trabajo de búsqueda, los objetivos eran dar cuenta del paso 
de la literatura chilena hay una literatura más, distinta a la de los y las escritoras, una historia literaria de los y las editoras. Es la historia literaria a la que se aproxima este trabajo, vislumbrando lo que se sabe -lo que he investigado y descubierto-y lo que no se sabe todavía, las preguntas que quedan.

El corpus de análisis, el número de ediciones revisado, está determinado por la oferta ofrecida en las fuentes digitales disponibles, debido a la dificultad de acceder a la Biblioteca Nacional en este tiempo de pandemia, por ello, he usado las digitalizaciones de la John Carter Brown Library y de Memoria Chilena, portal digital de la Biblioteca Nacional de Chile. De estos dos catálogos reuní 1270 ediciones, datadas desde 1776 hasta la actualidad; del periodo señalado he trabajado con cerca de 670 ediciones. Dicho corpus me ha permitido analizar el desarrollo temporal del peritexto editorial y ahondar en la diversidad de los actores involucrados, ya sean imprentas, editoriales, impresores, editores, editoras, que son parte de la historia del libro en mi país. Esbozar la historia literaria de los derechos de autor en el territorio nacional implica ahondar en la historia chilena del libro y en su historia legal, implica escribirlas algo más. Antes, sin duda, es necesario abordar teóricamente el peritexto editorial de derecho de autor, lo que se llevará a cabo a continuación.

\section{Peritexto editorial de derecho de autor}

Para caracterizar el peritexto editorial actual de derecho de autor es necesario primero entenderlo como un paratexto. La teorización de Gérard Genette es la base para esta investigación. El peritexto editorial de derecho de autor es un paratexto presente en los libros, texto paralelo al del autor, pues -como plantea Genette- el texto del autor raramente se presenta desnudo; todos los paratextos presentes (título, autor, prefacio) lo prolongan para presentarlo y darle presencia. ${ }^{2}$

Es interesante y necesario recalcar que Genette no presta atención al peritexto editorial de derechos de autor, o en su caso de copyright, pues sólo lo nombra entre las diversas indicaciones editoriales que se encuentran en la página legal, a las cuales da el nombre de peritexto editorial. De hecho, es fundamental especificar que la tradición chilena respecto del derecho de autor y

del copyright al copyleft, Creative Commons y anticopyright, de estrategias discursivas que respondían a un esquema común del gremio editorial y otras que daban cuenta de una creatividad literaria digna de ser considerada.

${ }^{2}$ Gérard Genette, Umbrales (México: Siglo XXI Editores, 2001), 7. 
del copyright sigue la vertiente francesa y no la anglosajona. El modelo estadounidense, el copyright, supone que el Estado brinda protección para alentar el progreso científico y literario, mientras que el modelo francés comprende que los derechos de autor son inherentes a la persona que ha creado la obra. En el caso chileno, un primer borrador de la Constitución de 1833 adoptaba el modelo estadounidense; sin embargo, finalmente se sigue el modelo francés de derechos de autor, lo cual confiere derechos de propiedad a los autores sobre sus creaciones, característica que sigue existiendo hasta nuestros días. ${ }^{3}$

Agregando a lo teorizado por Genette, el peritexto editorial de derechos de autor si bien prolonga la existencia del texto del autor y del libro, también es un paratexto marcadamente ideológico, sin duda vinculado al discurso legal y a los límites del uso del libro. El peritexto editorial de derecho de autor da cuenta de una mirada política-legal del editor, de la editorial, por tanto, no es un texto neutro, al menos no en la actualidad. A propósito, Andrea Palet ${ }^{4}$ destaca algunas características insoslayables del oficio de editor y una de ellas es el silencio, la capacidad de pasar desapercibido, de ser una sombra, de saber quedarse infinitamente callado: el editor como un fantasma. Sin embargo, sabemos que el editor también habla en el libro. Por ello, para continuar desde lo planteado por Genette, entenderé por peritexto editorial de derecho de autor un paratexto que, por supuesto, no corresponde al contenido del libro, que lo acompaña y versa sobre la propiedad intelectual del texto, derecho de autor, o de lo no permitido respecto al uso del libro (derecho de reproducción).

Por lo general, para el lector común y corriente, el peritexto editorial de derecho de autor no existe, pasa frecuentemente desapercibido en el acto de lectura. La hoja de créditos, la página legal donde se encuentra el peritexto editorial estudiado, se consulta en excepciones específicas, por ejemplo cuando el libro debe ser citado. Sin embargo, el peritexto editorial de derecho de autor existe, presenta un tono ideológico y legal, prohibitivo en la mayoría de los casos, que no ha sido escrito por el autor del libro y en el cual es posible hallar literatura en su desarrollo histórico. Para esta investigación es fundamental comprender la historia literaria del derecho de autor como otra historia literaria presente en la historia de la literatura en Chile, una historia paralela expresada en el

\footnotetext{
${ }^{3}$ Alberto Cerda, "Evolución histórica del Derecho de Autor en América Latina", Revista lus et Praxis 22, núm. 1 (2016): 23, 24.

${ }^{4}$ Andrea Palet, "Brevísimo manual para jóvenes editores", El Malpensante, núm. 115 (diciembre de 2010), acceso el 21 de septiembre de 2020, https://www.elmalpensante.com/ articulo/1734/brevisimo_manual_para_jovenes_editores.
} 
peritexto editorial estudiado, ¿menor que la historia literaria de los escritores? No lo sé. ¿Distinta? Sí, por supuesto.

El peritexto editorial de derecho de autor no siempre ha existido, ha tenido un inicio en la historia chilena del libro y, en la actualidad, es posible hallar otro tipo de paratextos de alternativas no legales al derecho de autor y al copyright: copyleft, Creative Commons y anticopyright. Durante el esbozo de la historia literaria del derecho de autor, se ahondará en los distintos tipos de paratextos relativos al control legal del libro y al derecho de autor entre 1776 y 1900, a saber: licencia católica de impresión, licencia estatal de impresión y peritexto editorial de derecho de autor. Asimismo, la exposición de la historia literaria del derecho de autor me permitirá profundizar en la historia editorial y del libro en Chile; sin embargo, el relato construido aquí no se rige por la división establecida por Bernardo Subercaseaux, sino que está determinado por las constituciones y legislaciones específicas del libro, por tanto, la división temporal está vinculada al desarrollo político-histórico chileno.

\section{Hacia la historia literaria del derecho de autor en Chile: desde las licencias católicas de impresión hasta el peritexto editorial de derecho de autor}

La historia literaria del derecho de autor en Chile convive con la historia del libro, de la tipografía y de la imprenta, al igual que con la historia legal del negocio del libro. Al pensarlo así, se presentan múltiples preguntas sobre lo investigado, por ejemplo: ¿cuál es el primer paratexto relativo al control legal del libro en el territorio chileno?, ¿cuál es el primer libro impreso que posee un peritexto editorial de derecho de autor?, ¿cuál es el primer libro impreso que usa la expresión derecho de autor?, ¿cuál es el primer libro impreso que nombra la palabra copyright?, ¿cuál es el primer libro impreso con el símbolo @?, ¿qué construcciones literarias hay en los peritextos editoriales de derecho de autor?, ¿en qué momento de la bibliografía chilena, en qué libro, en qué proyecto editorial se usa por primera vez una alternativa no reconocida legalmente al derecho de autor y al copyright?, ¿qué tan usado es el peritexto editorial de derecho de autor entre 1776 y 1900? Pues bien, comencemos.

El primer paratexto relativo al control legal del libro en Chile está en el primer librillo impreso en el territorio nacional: Modo de ganar el Jubileo Santo (1776), que contiene una licencia católica de impresión en su portada: "[c]on 
las licencias necesarias". ${ }^{5}$ Esta licencia es, entonces, el primer tipo de paratexto en la historia literaria del derecho de autor en Chile. Este concepto nace con la Real Pragmática de los Reyes Católicos en 1502 y se relaciona con el privilegio de impresión: "[u]n privilegio es una exclusiva que concede la autoridad a un solicitante (autor, editor, impresor) para la edición de una o varias obras, o un tipo (bulas, cartillas, etc.), para un territorio y durante un tiempo establecidos". ${ }^{6}$

El privilegio de impresión en España nace también ante la necesidad de proteger las impresiones originales de las ediciones falsificadas y, a su vez, es parte de un sistema de censura sobre la impresión, la circulación de libros y la lectura. Además, hay que aclarar que el privilegio de impresión y la licencia católica de impresión no son sinónimos. Según Marcela Zúñiga Saldaña, la licencia era el trámite obligatorio para cualquier texto que se quisiera imprimir, mientras que el privilegio era el monopolio concedido por el rey para la impresión de una obra determinada, lo cual permitía que nadie más pudiese imprimirla. Por tanto, la licencia católica de impresión era la manifestación textual del permiso entregado por el rey o por quien fuese el dueño del privilegio, para la impresión, distribución y venta de un libro. ${ }^{7}$

La historia de la legislación de los Reyes Católicos sobre el control legal del libro comienza en 1502, a 31 años de iniciada la impresión tipográfica y a 21 años de la llegada de Cristóbal Colón a América, cuando dictan la Real Pragmática, la cual ordena que nadie pueda hacer la impresión tipográfica de un libro en latín o en romance sin que primero tenga la licencia para hacerlo. Si una persona contravenía lo anterior e imprimía sin dicho permiso, el castigo era la pérdida de los mismos libros, que serían quemados en la plaza de armas. Gracias a lo aportado por Amparo García Cuadrado sabemos que el privilegio de impresión, mediante las respectivas licencias verbal o textualmente conferidas, se otorgaba desde mucho antes, pues esta autora menciona que los privilegios datan de 1490. Además, su práctica comienza en Italia, en Milán, en 1481, cuando Andrés de Bossis obtuvo el privilegio de impresión de la obra Sforziada,

\footnotetext{
${ }^{5}$ Anónimo, Modo de ganar el Jubileo Santo (Santiago, 1776), 1.

${ }^{6}$ Fermín de los Reyes Gómez, "El privilegio de los Diccionarios de Antonio de Nebrija (siglos XV-XVIII): otro enredijo de mil diablos", Corpus Eve. Émergence du Vernaculaire en Europe (2014): 1, https://doi.org/10.4000/eve.850.

${ }^{7}$ Marcela Zúñiga Saldaña, "Privilegios para imprimir libro en la Nueva España, 1714-1803. La renta de un monopolio editorial", Estudios del Hombre, núm. 20 (2005): 60, 61, 63, acceso el 21 de septiembre de 2020, http://148.202.18.157/sitios/publicacionesite/pperiod/ esthom/esthompdf/esthom20/59-86.pdf.
} 
de Juan Simoneta. ${ }^{8}$ La legislación de la monarquía española marcó el inicio del control legal del libro en España y sus colonias.

Este control ejercido por el rey se basaba en que, a priori, tenía el poder de permitir o negar la impresión o venta de un libro, lo cual significaba que él ostentaba el gobierno de la censura a través de la comercialización, el control legal del negocio de impresión. Asimismo, los Reyes Católicos legalizaron por primera vez el privilegio económico en la explotación de una obra, lo cual en la historia que estoy contando es fundamental, pues, desde mi perspectiva, en la Real Pragmática de 1502 se sientan las bases del negocio en torno al libro, sobre todo con el concepto de exclusividad del privilegio de impresión -que perdura hasta la actualidad en el copyright y en el derecho de reproducción-, transformándose en un pilar inamovible que permite el monopolio sobre un contenido. En el privilegio de impresión dicho monopolio estaba concedido por el rey, no por los autores; ahí radica la diferencia, por ello el privilegio de impresión y las licencias no constituyen derecho de autor. ${ }^{9}$

El desarrollo histórico de la legislación en torno al privilegio de impresión y a la licencia católica es extenso de resumir, y es necesario avanzar en la historia; sin embargo, vale la pena hablar de lo que la legislación refiere sobre América. La primera legislación que trata sobre el libro y América es la Real Cédula de 1531, que "prohibía el envío para las Indias de libros de romance, de historias vanas y profanas". ${ }^{10}$ Luego, en 1539 se establece la sucursal de la imprenta de Juan Cromberger en Ciudad de México, con el impresor Juan Pablos a cargo. En Chile, la primera imprenta se rastrea en el siglo XVI, con las impresiones de naipes. ${ }^{11}$ Los tipos móviles ingresan a la imprenta en 1776, como sabemos.

Bernardo Subercaseaux plantea que en la Colonia no hubo actividad editora ni de imprenta y, por tanto, establece que los primeros impresos son el libro titulado Carta de un americano a un español y el periódico La Aurora de Chile,

\footnotetext{
${ }^{8}$ Amparo García Cuadrado, "Aproximación a los criterios legales en materia de imprenta durante la Edad Moderna en España", Revista General de Información y Documentación 6, núm. 2 (1996): 127-128.

${ }^{9}$ Camilo Mirosevic, "Origen y evolución del derecho de autor, con especial referencia al Derecho chileno", Revista de Derecho de la Pontifica Universidad Católica de Valparaíso 28, núm. 1 (2007): 40.

10 José Torre Revello, El libro, la imprenta y el periodismo en América durante la dominación española, ed. facs. (México: UNAM, IIB, 1991), 37-38.

11 Jorge Soto Veragua, La historia de la imprenta, desde el siglo XVIII hasta el XXI (Santiago: El Árbol Azul, 2009), 32.
} 
ambos de 1812, y si reconoce tal actividad, la desdeña. ${ }^{12}$ Es relevante para esta historia el hecho de que Subercaseaux no haya considerado la existencia del Modo de ganar el Jubileo Santo (1776) como el primer impreso en Chile. Este librillo religioso fue descubierto por Ramón Laval en la biblioteca de Ramón Briseño, comprada por el Estado chileno en 1901. Hasta ese momento, tanto José Toribio Medina como Luis Montt consideraban que una esquela de invitación y la tesis universitaria Hesperiae Monarchae Indiarumque Imperatori, de José Ignacio Gutiérrez, eran los primeros impresos chilenos (ambos de 1780) salidos de la misma prensa, atribuida por Montt al tallador Rafael Nazával. ${ }^{13}$

Sin embargo, Alamiro de Ávila Martel contradice la opinión de Montt y afirma que la incógnita sigue abierta. Además, en las prensas del Modo de ganar el Jubileo Santo, de acuerdo con Ávila se imprimieron "dos tesis universitarias del año 1780, dos esquelas de convite de la misma data y cinco hojas, impresas por una sola cara, que contienen reglamentos de la Recolección Dominicana, dados por el padre Sebastián Díaz, en 1783. Después de este año desaparece esa tipografía". ${ }^{14}$

Sobre la estructura lingüística de la licencia de impresión, es interesante apuntar que la legislación hasta el momento, desde la Real Pragmática de 1502 en adelante, no establece una forma tipo, por lo cual quedaba al arbitrio de quien la redactaba, del impresor o del editor. En el caso del Modo de ganar el Jubileo Santo, la licencia católica de impresión en la portada presenta la estructura textual escueta que se observa en la tradición de las licencias de la imprenta española y mexicana: "[c]on las licencias necesarias". Importa decir que no se sabe quién otorgaba la licencia. Por otra parte, Ávila menciona que el Modo de ganar el Jubileo Santo no cumple con toda la ordenanza sobre la publicación de rezos en territorios americanos, pues "el impreso debía ser tasado y llevar estampado su precio, lo que vemos que no se cumplió". 15

Ávila también plantea la existencia de una imprenta de tipos móviles traída por los jesuitas a Chile en 1748 y que no fue usada, así como la aparición de una segunda caja de tipos en 1787, con la cual sólo se imprimieron esquelas

\footnotetext{
${ }^{12}$ Bernardo Subercaseaux, Historia del libro en Chile. Desde la Colonia hasta el Bicentenario (Santiago: LOM Ediciones, 2010), 16-17.

${ }^{13}$ Ramón Laval, Un incunable chileno. Modo de ganar el Jubileo Santo (Santiago: Imprenta Universitaria, 1910), 10, 12.

${ }^{14}$ Alamiro de Ávila Martel, El Modo de ganar el Jubileo Santo de 1776 y las imprentas de los incunables chilenos (Santiago: Imprenta Universitaria, 1976), 16, 27.

15 Ibid., 33.
} 
de invitación entre 1787 y 1789, y la que poseía José Camilo Gallardo, que contenía la caja de tipos de $1787 .{ }^{16}$ La producción de J. C. Gallardo comienza con el Directorium pro diuino officio en 1801, y se desarrolla bajo la legislación monárquica. Sin embargo, la portada de esta edición no contiene paratexto relativo a la licencia católica de impresión.

Es importante advertir que la publicación de libros no fue una actividad principalmente realizada en la imprenta de J. C. Gallardo durante la Colonia, sino que deviene con la Independencia, proceso que se inicia en 1810 con la Primera Junta de Gobierno de Chile. Una medida del gobierno provisorio fue la compra estatal de una imprenta -la primera de tipos móviles, según Subercaseaux-, nombrada "Imprenta del Gobierno", con la que se imprimió el periódico ministerial y político La Aurora de Chile. Como sabemos, esta imprenta provenía de Estados Unidos con 3 tipógrafos: Samuel B. Johnston, Guillermo H. Burbidge y Simon Garrison, que serían los impresores del periódico. ${ }^{17}$

En la España monárquica, la legislación también cambiaba durante ese periodo, pues las Cortes de Cádiz promulgaron en 1810 el decreto referente a la libertad de imprenta, además de establecer que los libros religiosos "debían someterse a la censura de los ordinarios eclesiásticos, de acuerdo con lo establecido en el Concilio de Trento". ${ }^{18}$ A partir de este decreto no todos los libros necesitarían de licencia para su estampa, de tal manera que la hegemonía del privilegio de impresión parece quebrarse con la libertad de imprenta.

Por ejemplo, en 1812 Samuel B. Johnston y Simon Garrison publicaron dos obras que no poseen frase alguna relativa a la licencia católica de impresión: el Reglamento constitucional provisorio del Pueblo de Chile y la Carta de un americano a un español. ¿Estas ediciones serán producto de una imprenta libre de la legislación monárquica sobre la imprenta y el libro? Lo más probable es que sean las primeras que nacen en territorio nacional desde una concepción distinta al control legal del libro de la monarquía española, pues el Reglamento constitucional provisorio es la primera legislación en Chile que dictamina la libertad de imprenta: "[l]a imprenta gozará de una libertad legal; y para que esta no degenere en licencia nociva à la Religión, costumbres y honor de los ciudadanos y del pais; se prescribirán reglas por el Gobierno y Senado".19

\footnotetext{
16 Ibid., 39-44.

17 Subercaseaux, Historia del libro en Chile, 30, 33.

18 Torre Revello, El libro, la imprenta y el periodismo, 51.

${ }^{19}$ Reglamento constitucional provisorio del Pueblo de Chile (Santiago de Chile: Imprenta del Gobierno, 1812), 9.
} 
Pese a la declaración del Reglamento provisional de 1812, es posible encontrar ediciones posteriores al mismo con licencias católicas de impresión y ligadas a J. C. Gallardo, quien en 1813 estaba a cargo de la Imprenta del Estado - Imprenta del Gobierno e imprimió el periódico El Monitor Araucano y el Semanario Republicano de Chile. Su labor no sólo se relaciona con la prensa de su época, sino también con algunas obras publicadas por él, que cuentan con licencia católica de impresión. Primero encontramos el Convento Espiritual, impreso en 1813 y que contiene licencia católica en su portada: "[c]on las licencias necesarias". ${ }^{20}$ Segundo, en la Demostracion teologica de la plena, y omnimoda autoridad que por derecho divino y sin dependencia alguna del Papa tienen los obispos dentro de sus respectivas diocesis, impresa también por Gallardo en 1813, se aprecia la misma licencia, ${ }^{21}$ y en Cathedra de prima de sagrados canones, impresa en 1816 por el mismo, la edición exhibe en su portada la licencia católica de impresión. ${ }^{22}$ Estas licencias aparecen debido a que los textos son de temática religiosa, por tanto, necesitan de autorización, como lo dictamina el decreto IX de las Cortes de Cádiz en 1810. De hecho, Patricio Ibarra destaca cómo los primeros gobernantes tomaron en cuenta la legislación de las Cortes de Cádiz sobre imprenta para elaborar el Reglamento provisional de $1812 .{ }^{23}$

Es necesario indicar que, por una parte, no todas las ediciones impresas por J. C. Gallardo poseían alguna frase relativa a la licencia católica de impresión, ya que si revisamos los siguientes títulos: Proyecto de una constitución para el Estado de Chile (1813), Tarifa ó regulación de los precios de medicamentos simples y compuestos... (1813), Directorium ad horas canonicas persolvendas... (1814), Clamor del Estado religioso (1814) y Sermón de nuestra santísima madre de Mercedes (1815), no encontraremos la licencia católica de impresión. En los dos primeros casos es entendible su ausencia, puesto que las leyes, textos legislativos, listas de precios o medicamentos, por lo general, no han contado con la protección del derecho de autor.

\footnotetext{
20 Una religiosa capuchina, Convento Espiritual (Santiago: José Camilo Gallardo, 1813), 1.

${ }^{21}$ Fernando García, Demostracion teologica de la plena y omnimoda autoridad que por derecho divino y sin dependencia alguna del Papa tienen los obispos de sus respectivas diocesis (Santiago: Imprenta del Superior Gobierno, 1813), 1.

22 Biblioteca Nacional, Impresos chilenos 1776-1818. Vol. 1 (Santiago: Biblioteca Nacional, 1963), 278.

${ }^{23}$ Patricio Ibarra Cifuentes, "Liberalismo y prensa: Leyes de imprenta en el Chile decimonónico (1812-1872)", Revista de Estudios Históricos-Jurídicos, núm. 36 (2014): 297.
} 
Por otro lado, en otras obras que imprime Gallardo usa otro peritexto que también se encuentra en el Discurso sobre la insurrección de América, que escribia el dr. Quixano, secretario que fue del gobierno revolucionario de Quito, libro de 1816 salido de la Imprenta del Gobierno, con Gallardo como maestro impresor. Esta edición tiene en su portada la licencia católica de impresión: "[c]on permiso superior". En las Oraciones, y alabanzas en forma de trisagio a la santisima virgen maría nuestra señora, en el misterio, de su gloriosa asumpcion a los cielos (Santiago de Chile, 1816), libro reimpreso por Gallardo, se lee también en la portada: "[c]on Superior permiso". ${ }^{24}$

Considerando que estos libros fueron impresos durante la reconquista española, ¿el paratexto "con permiso superior" será una alternativa a "con las licencias necesarias"?, ¿quiénes serían las autoridades de las cuales emanaron esas licencias?, ¿se podría hablar de dos modelos de construcción lingüística de la licencia católica de impresión?, ¿por qué José Camilo Gallardo utiliza licencias católicas de impresión en 1813, cuando en 1812 se declaró la libertad de imprenta?, ¿durante este periodo existirían otros impresores en ejercicio, además de los tipógrafos estadounidenses y J. C. Gallardo?

Respecto de la última pregunta, es importante destacar que había otros dos impresores durante este periodo: el primer nombre distinto que vemos aparecer en la bibliografía chilena es Eusebio Molinare, quien, al estar a cargo de la Imprenta del Estado imprimió en 1817 El amigo de la llustración, de Francisco Calvo. Ese mismo año Molinare sacó a la luz las Exequias dedicadas el día 4 de noviembre de 1817 por el supremo gobierno de Chile a la ilustre memoria de los mártires de la libertad en la sangrienta batalla del 1 y 2 de octubre de 1814 en la Ciudad de Rancagua. En 1818, Antonio Xara y Eusebio Molinare imprimieron el Manifiesto que hace a las naciones el director supremo de Chile de los motivos que justifican su revolución y la declaración de su independencia. Y Xara editó una hoja titulada Viva la patria, con la Imprenta de Chile Independiente. Las respuestas a las otras preguntas siguen siendo una incógnita.

Con el desarrollo constitucional del Estado chileno, la nación no sólo se afianzó en su autonomía territorial y política, también se desvaneció el control legal de la monarquía sobre la producción editorial del país; sin embargo, existen ediciones posteriores a 1818 que aún presentan licencias católicas de impresión, por ejemplo, en 1873 la Imprenta de El Correo del Sábado dio a la luz

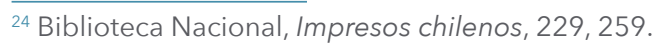


el libro La virjen [sic] del Andacollo, del presbítero Juan Ramón Ramírez, y en tal edición aparece la aprobación del Ordinario:

ILTMO. SEÑOR OBISPO. En virtud de la honrosa comisión que V. S. I. se dignó conferirme, he leído detenidamente el opúsculo que ha escrito el señor presbítero don Juan Ramon Ramirez, cuyo título es: La Virjen de Andacollo.- Reseña histórica de todo lo que se relaciona con la milagrosa imájen que se venera en aquel pueblo. En mi humilde concepto juzgo mui digno de la impresion i publicacion el opúsculo que me ocupa. Su lectura a la vez que es amena y agradable, conseguirá sin duda arraigar mas en los corazones piadosos la devoción tan distinguida i universal que hoi dia existe por ese simpático santuario de Andacollo, como asimismo cautivará muchos corazones frios e indiferentes.- Es cuanto puedo informar en obsequio de la verdad.- Serena, agosto 27 de 1873. Jerman Donoso. Serena, agosto 28 de 1873. Con lo informado por el revisor del opúsculo titulado La Virjen de Andacollo.- Reseña histórica de todo lo que se relaciona con la milagrosa imájen que se venera en aquel pueblo, escrito por el presbítero don Juan Ramon Ramirez, se permite su impresión. El Obispo. ${ }^{25}$

La presencia de esta licencia católica de impresión demuestra la manera en que, al parecer, conviven dos sistemas legales: el católico y el chileno, como si se tratase de un terreno en constante tensión, lo cual evidencia también que los conceptos de derecho de autor, propiedad intelectual, derecho de reproducción, no fueron creados de inmediato en el desarrollo de la ley, ni a la par de la libertad de imprenta como legislación. Todos estos conceptos tienen una historia en el desarrollo de la legislación sobre la publicación de la opinión pública y la imprenta. Ahondé en el tema, buscando saber si el peritexto editorial de derecho de autor era una disposición legal, con un modelo textual, o era una construcción creada por los impresores y autores en el siglo XIX.

La legislación monárquica, que permite el control legal del libro en España y sus colonias, y las licencias católicas de impresión quedaron sin efecto por primera vez en 1812, con el Reglamento constitucional provisorio del Pueblo de Chile, subscripto por el de la capital, presentado para su subscripcion a las provincias, sancionado y jurado por las autoridades constituidas, legislación chilena cuyo artículo XXIII establece: "[I]a imprenta gozará de una libertad legal; y para 25 Juan Ramón Ramírez, La virjen de Andacollo (La Serena: Imprenta de El Correo del Sá-
bado, 1873), 4. 
que esta no degenere en licencia nociva á la Religión, costumbres y honor de los ciudadanos y del pais; se prescribirán reglas por el Gobierno y Senado". Esta libertad de imprenta sólo se sostiene desde una oposición entre lo bueno y provechoso, y lo perverso y perjudicial. Tal oposición está marcada por la presencia de la religión católica en el marco regulatorio legal y cultural de la sociedad. De hecho, el artículo I establece que la religión católica, apostólica y romana es la religión de Chile. ${ }^{26}$

En 1813 apareció el "Decreto del Gobierno con acuerdo del Senado sobre la libertad de la prensa", que evidencia la definición en la legislación específica de la libertad de imprenta sobre los procedimientos de vigilancia y censura:

I. Habrá desde hoy entera y absoluta libertad de imprenta. El hombre tiene derecho de examinar cuantos objetos estén a su alcance; por consiguiente, quedan abolidas las revisiones, aprobaciones y cuantos requisitos se opongan a la libre publicación de los escritos.

II. Siendo la facultad que los hombres tienen de escribir con la limita de que se guarde decoro y honestidad, faltar a esta condición es un delito. Si el que falta agravia a un tercero, a este corresponde la acusa ante la junta Protectora, de que después se hablara. Si el escrito publicado expone la seguridad y tranquilidad pública, la Religión del Estado o el sistema de Gobierno, a todos los ciudadanos y en especial al Ministerio Fiscal. Tan sagrada a inviolable es a los ojos de la ley la reputación de los gobernantes o Supremos Magistrados, como la de los ciudadanos particulares y en esta materia, todos tienen el mismo derecho a quejarse...

IX. De todo escrito es responsable su autor; y si es anónimo; el impresor, quien también debe responder de la publicación de un escrito religioso sin la censura dispuesta en el articulo VIII.

$X$. Todo ciudadano que directamente, por amenazas o de otro cualquier modo indirecto, atentase contra la libertad de la Imprenta; se entiende que ha atacado la libertad nacional: deben imponérsele las penas correspondientes a este delito, y principalmente la de privársele en adelante de los derechos de ciudadanía. ${ }^{27}$

${ }^{26}$ Reglamento constitucional provisorio, 4, 9.

27 "Decreto del Gobierno con acuerdo del Senado sobre la libertad de la prensa", El Monitor Araucano, t. 1, núm. 35, 26 de junio de 1813. 
Es peculiar que este decreto específico para la libertad de imprenta evidencie la responsabilidad moral del autor por el contenido de su obra, responsabilidad moral que, en estricto rigor, estaba vinculada tanto a la libertad de expresión como al derecho de autor. Si por todo escrito es responsable su autor, implícitamente se reconoce que el texto es de su propiedad, es un texto que nace desde la libertad de expresión.

Mirosevic explica de la siguiente manera la relación entre la libertad de expresión y el derecho de autor: "para que exista un derecho sobre la creación (derecho de autor o propiedad intelectual) es necesaria la existencia de un derecho a crear, sustrato del primero (y como la creación se produce en el intelecto y se manifiesta a través de la expresión, este derecho corresponde, precisamente, a la libertad de expresión)". ${ }^{28}$ Por ello, el contenido podía ser vigilado, juzgado o censurado, se podía considerar una obra como un delito, un oficio penado con la pérdida de la ciudadanía, dejando a un escritor en condición apátrida. Esta legislación no permitía pensamientos disidentes en su territorio.

Luego de la reconquista, y debido al proceso de independencia de 1818, la legislación monárquica volvió a quedar sin efecto con el Proyecto de constitución provisoria para el Estado de Chile, publicado en 1818, que en su artículo $\mathrm{XI}$ versa sobre la libertad de imprenta, continuando con la tradición liberal, pero a la vez punitiva. De hecho, el mismo proyecto declara que el Estado tiene religión, y la suya es la religión católica, apostólica y romana. ${ }^{29}$

Esta marca de la religión católica en el desarrollo constitucional es fundamental, pues de nueva cuenta impone una perspectiva moral sobre la libertad de expresión, lo cual repercute, implícitamente, en la autoría y la publicación de un libro, en la libertad de imprenta, que se vuelve a declarar en la Constitución de 1822; de hecho, primero en el artículo 47, punto 23 del texto constitucional, se sostiene que al Congreso le corresponde proteger la libertad de imprenta. Segundo, desde el artículo 223 se comienza a dar cuenta de mínimas especificaciones sobre el comercio del libro y que se establecerán en el territorio nacional instituciones inquisitoriales. ${ }^{30}$

Esta falta de claridad sobre el tema de la impresión en la Constitución de 1822 se reconsidera en la de 1823, legislación que nuevamente no sólo tiene

\footnotetext{
${ }^{28}$ Mirosevic, "Origen y evolución del derecho de autor...", 44.

29 Proyecto de constitución provisoria para el Estado de Chile (Santiago: Imprenta del Gobierno, 1818), 4, 7-8.

${ }^{30}$ Constitución política del Estado de Chile (Santiago: Imprenta del Estado, 1822), 19, 70-72.
} 
en cuenta el derecho de publicación, sino también la obligación moral del autor sobre el contenido de su obra:

Art. 262. La imprenta será libre, protegida y premiada en cuanto contribuya a formar la moral y buenas costumbres; al examen, y descubrimientos útiles de cuantos objetos pueden estar al alcance humano; a manifestar de un modo fundado las virtudes cívicas y defectos de los funcionarios en ejercicio; y a los placeres honestos y decorosos.

Art. 263. Se le prohibe: $1 .^{\circ}$ Sindicar las acciones de algún ciudadano particular, ni las privadas de los funcionarios públicos. $2 .^{\circ}$ Entrometerse en los misterios, dogmas y disciplina religiosa, y la moral que generalmente aprueba la Iglesia Católica...

Art. 265. Todo escrito que ha de imprimirse, está sugeto al consejo de hombres buenos, para el simple y mero acto de advertir á su autor las proposiciones censurables.

Art. 266. Hecha la advertencia, puede el autor corregirlas por sí, ó vindicarlas en un juicio público en el Tribunal de libertad de Imprenta, sin costos, sumarisimo y sugeto á la mera inspeccion de las proposiciones censuradas; y no queda responsable despues de la publicacion. Si no quiere corregir, ni vindicar sus proposiciones en éste juicio, puede publicarlas sujeto á la pena legal establecida para aquel abuso de Imprenta, si se juzgase tal; y en este caso solo debe imprimirse si el autor es persona de abono ó afianza la responsabilidad civil. ${ }^{31}$

Este derecho de autor implícito, manifiesto en la obligación moral del autor sobre el contenido de su obra, cuando ejerce la libertad de expresión, se basa nuevamente en la perspectiva moral sobre las dos caras del libro, lo que es su peligro. Y -como podemos observar- hay juicio, jueces, penas legales, lo usual. Además, hasta ese momento no existe nada acerca de un modelo de indicación relativa al derecho de autor. De hecho, una edición de 1822 permite cuestionar el paso de la licencia católica de impresión hacia el derecho de autor, pues la transición en realidad sería desde aquélla hasta la licencia estatal de impresión.

En este caso, la licencia estatal de impresión de una obra era solicitada a la máxima autoridad en la jerarquía estatal, supongo que se daba dicha licencia por el financiamiento de la publicación. Esta licencia estatal se nos muestra en

${ }_{31}$ Constitución política del Estado de Chile (Santiago: Imprenta Nacional, 1823), 74-76. 
el libro titulado Descripción de la verdadera, y falsa vacuna, y modo de ingerir el fluido vacuno, con los accidentes que acaecen antes y despues de su ingercion, de Manuel Grajales, impreso en 1822 en la Imprenta Nacional, en donde puede leerse el siguiente diálogo impreso:

Tengo el honor de dirigir á V. S. el adjunto extracto que describe el método mas sencillo de ingerir y conocer la verdadera y falsa vacuna, con algunos accidentes, que sobrevienen de esta \&c.: para que sirva V. S. elevarlo á manos de S. E. el Supremo Director del Estado, á fin de que fuese de su agrado, le mandé imprimir con el objeto de que todos los del pueblo puedan aprender por sí esta loable operacion que es digna de la proteccion de S. E., quien no dudo pondrá todos los medios de su alto poder porque se perpetüe en este Estado y se lleve á debido efecto la conservacion y propagación de este fluido, que ha dado mas vidas y ha evitado mas lágrimas a los padres amantes de sus hijos que arenas hay en la mar. He procurado en esta disertación buscar la claridad y brevedad: no por eso pienso que sea la mejor, pero con la proteccion de la supremacia quedo satisfecho. Dios guarde á V. M. muchos años. Santiago de Chile Junio 26 de 1822.- Manuel Grajales. - Señor Ministro de Estado en el departamento de gobierno. Santiago $1 .^{\circ}$ de 1822 Imprimanse quinientos ejemplares para que se circulen á los pueblos, encargando á las municipalidades el adoptar su método, y generalizarlo en todas las poblaciones y campañas. Contestese á D. Manuel Julian Grajales dándole las gracias á nombre de la Patria por este recomendable servicio tan útil á la salud pública.- O'higgins.- Echeverría. ${ }^{32}$

Es interesante que esta licencia estatal de impresión no aparezca descrita como un mecanismo de publicación de una obra en ninguna legislación constitucional o particular. Por el momento, no puedo dar más evidencia acerca de este modelo textual; sin embargo, el caso demuestra la existencia de un paso más entre la licencia católica de impresión y el derecho de autor, y es una veta de investigación a futuro, pues implica ahondar en la escena impresora entre los años 1817 y 1833 , en las ediciones producidas durante ese periodo, sobre todo las vinculadas al Estado y su desarrollo legal y reglamentario, y a la Iglesia católica y las publicaciones con temática religiosa, pues no sólo importa hallar

\footnotetext{
32 Manuel Grajales, Descripción de la verdadera, y falsa vacuna, y modo de ingerir el fluido vacuno, con los accidentes que acaecen antes y despues de su ingercion (Santiago: Imprenta Nacional, 1822), 3.
} 
más licencias estatales de impresión, sino saber si hay más licencias católicas. Es probable que existan licencias católicas de impresión y licencias estatales en impresiones de hojas sueltas, invitaciones, avisos, versos sueltos, bandos y proclamas, así como en impresiones de la prensa de la época, un corpus que excede el foco de esta investigación.

La primera escena de imprenta en el Chile independiente abarca desde 1818 hasta 1833, límite que hemos puesto en relación a la creación de la Constitución de ese año. La bibliografía está compuesta por el trabajo de los siguientes establecimientos de impresión: Imprenta del Gobierno o Imprenta del Estado (1812), Imprenta de Valles y Villagrán (1819), Imprenta de Valles y Vilugrón (1820), Imprenta Nacional (1820), Imprenta de la Biblioteca (1820), Imprenta de Valdés (1820), Imprenta de la Independencia (1820), Imprenta de Julio Belín y Ca. (18201859), Imprenta de la República (1821), Imprenta del Mercurio (1823, Valparaíso), Imprenta de D. Estevan Valles (1823), Imprenta de La Sociedad (1823), Imprenta de Pérez (1824), Imprenta del Instituto (1824, Coquimbo), Imprenta de R. Rengifo (1825-1831), Imprenta de La Opinión (1828), Imprenta de N. Ambrosy y Ca. (1828), Imprenta Republicana (1829), Imprenta de La Bandera, Imprenta de la Federación (1829) e Imprenta de Colocolo (1830).

La publicación gubernamental fue uno de los primeros motores para la escena impresora desde 1811, tanto para libros como para otros formatos y géneros, por ejemplo el bando, la proclama y la prensa. Con la entrada de la Imprenta de Valles en 1823, apareció el nombre de otro maestro impresor: Pérez, quizá dueño de la Imprenta de Pérez, donde se imprimieron entre 1824 y 1825 las obras Devota novena del glorioso y angelico joven S. Luis Gonzaga de la Compañia de Jesus, de Bernardino Bilbao; el Breve manual para administrar los sacramentos del bautismo, extrema-unción y sagrada comunión, y las Conmemoraciones votivas para el coro de los conventos franciscanos, de Gregorio Vázquez. Además, fundamental fue el trabajo editorial de la Imprenta de Ramón Rengifo, que comenzó hacia 1825.

Otro impresor fue M. Peregrino, quien trabajaba con la Imprenta Nacional en 1830. Eusebio Molinare aparece como maestro impresor en la Imprenta de N. Ambrosy y Ca., pues en la portada de las ediciones que he visto -como la Contestacion al manifiesto de algunas municipales, sobre la discusión y resultados de la cuenta de D. Miguel Francisco Trucios, impresa en 1828- está su nombre; es el mismo fenómeno de la Imprenta de Valles y el impresor Pérez. Además, Molinare administró la Imprenta de La Federación en 1828. 
A propósito, la preocupación y discusión, la voz pública de los impresores a favor de la libertad de imprenta, en especial acerca de los abusos, es parte de su trabajo; les incumbe saber y atenerse a las reglas del juego; la legislación resulta imprescindible y se espera que el editor tenga una visión al respecto. Es interesante que esa preocupación pueda apreciarse materialmente en alguna edición; así parece cuando veo en la portada de Cartas pehuenches (Imprenta de Gobierno, 1820), la cita de la legislación: "Todo hombre tiene libertad para publicar sus idéas, y examinar los objetos que están á su alcance. \&c. Const. Prov. de Chile, tit. 1, art. 11". ${ }^{33}$ ¿Será que la cita previene a las personas que tratasen de censurar el libro de no hacerlo, debido a la libertad de imprenta?

En la historia legal sobre el libro, la libertad de imprenta vuelve a ser legislada en la Constitución de 1828, la cual especifica que la nación asegura al hombre ciertos derechos, uno de ellos es la facultad de imprimir sus opiniones, y sobre la libertad de imprenta mantiene la misma perspectiva. ${ }^{34}$ La ley sobre abuso de la libertad de imprenta de 1828 regula la inscripción de imprentas, los juicios de imprenta, la publicación de libros, sobre la cual obliga al impresor a indicar en lo que estampe el nombre de la imprenta y año de impresión, pero no obliga a marcar textualmente la propiedad literaria o el privilegio de impresión.

La siguiente Constitución (1833) posee una significativa particularidad, pues explicita la propiedad intelectual, el derecho de autor. Dice el artículo 152: "[t]odo autor ó inventor tendrá la propiedad esclusiva de su descubrimiento, ó producción, por el tiempo que le concediese la lei; y ésta exijiere su publicacion nacional, se dará al autor la indemnizacion competente". ${ }^{35}$ Se establece por vez primera, de manera explícita, el derecho de autor en términos de propiedad intelectual, junto con la lógica del derecho moral y patrimonial, ya que en la ley se estipula que el autor puede recibir un pago por su trabajo, por la publicación de su obra. Así, la Constitución de 1833 se inscribe en la visión francesa del derecho de autor y se aleja, definitivamente, de la perspectiva del copyright.

Además, en 1834 se publica la Lei de privilegio esclusivo, que regula la propiedad intelectual en el territorio chileno, y establece en su artículo primero que

33 Juan Egaña, Cartas pehuenches, o correspondencia de dos indios naturales del PireMapu, ó sea la quarta en Los Andes, el uno residente en Santiago, y el otro en las cordilleras pehuenches (Santiago: Imprenta de Gobierno, 1820), 1.

${ }^{34}$ Constitución política de la República de Chile (Santiago: Imprenta de R. Rengifo, 1828), 3.

${ }^{35}$ Constitución de la República de Chile jurada y promulgada el 25 de mayo de 1833 (Santiago: Imprenta de La Opinión, 1833), 43. 
Los autores de todo jenero de escritos, ó de composiciones de música, de pintura, dibujos, escultura y en fin de aquellos á quienes pertenece la primera idea en una obra de literatura ó de las letras, tendrán el derecho esclusivo, durante su vida, de vender, hacer vender ó distribuir en Chile sus obras por medio de la imprenta, biografía molde, ó cualquiera otro medio de reproducir ó multiplicar las copias. ${ }^{36}$

Es relevante el carácter económico de este artículo, pues predispone que el escritor vende o hace vender su obra mediante la reproducción de copias impresas; por ello, es necesario entender el derecho de reproducción como parte del derecho de autor.

Además, esta ley en su artículo décimo plantea unas exigencias para la impresión de un libro: "[p]ara entrar en el goce de los derechos concedidos por los artículos anteriores, no se necesita título alguno del Gobierno, y bastará que depositándose previamente tres ejemplares de la obra en la biblioteca pública de Santiago, se anuncie en el frontispicio a quien pertenezca"; lo primero, la ausencia de una licencia de impresión como base en el goce de los derechos, se convierte en un punto de inflexión en el desarrollo de la legislación chilena sobre libertad de imprenta y propiedad intelectual. Por otra parte, esta ley sólo dispone que "se anuncie en el frontispicio a quien pertenezca", ${ }^{37}$ por tanto, si el paratexto relativo a la propiedad intelectual o al derecho de autor no estaba mandatado por la ley, significa que en esa época el peritexto editorial de derecho de autor era una creación del impresor, editor o autor.

De 1833 hasta 1900 son los límites del periodo para buscar el primer peritexto editorial de derecho de autor. Además, en esta etapa se observa un crecimiento en el número de talleres de imprenta, que se desarrollan junto a las imprentas mencionadas: Imprenta del Comercio (hay dos homónimas, una en Santiago entre 1836 y 1906, y otra en Valdivia entre 1826 y 1908), Imprenta Cervantes (de Rafael Jover, funcionó entre 1877 y 1930), Imprenta Chilena (18451902), Imprenta de la Unión Americana (1864-1870), Imprenta de P. Ramírez (Valparaíso, 1889-1893), Imprenta del Centro Editorial (1879-1897), Imprenta del Ferrocarril (1850-1875), Imprenta del Progreso (1842-1893), Imprenta El Patriota (1890-1906), Imprenta Esperanza (1902-1904), Imprenta Estrella de Chile

\footnotetext{
${ }^{36}$ Ley S/N, "Privilejio exclusivo", de 24 de julio de 1834, Ley Chile, Biblioteca del Congreso Nacional de Chile, acceso el 21 de septiembre de 2020, https://www.leychile.cl/ $N ? i=1016800 \& f=1835-01-10 \& p=$.

$37 \mathrm{lbid}$.
} 
(1886-1892), Imprenta La Sin Rival (1890-1903), Imprenta Victoria (1855-1890), Imprenta y Encuadernación Barcelona (1892-1913), Centro Editorial La Prensa (1895-1906), Establecimiento Poligráfico Roma (1890-1899), Establecimiento Tipográfico de La Época (1882-1889), Imprenta Andrés Bello (1873-1900), Imprenta B. Morán, Imprenta de El Constituyente (1876-1878), Imprenta de El Correo (1875-1906), Imprenta de El Sur (Concepción, 1884-1907), Imprenta de Emilio Pérez (1892-1905), Imprenta de La Gaceta (1893-1898), Imprenta de La Libertad (Iquique, 1883), Imprenta de La Patria (Valparaíso, 1861-1898), Imprenta de Los Debates (1888-1891), Imprenta de Los Tiempos (1870-1880), Imprenta de M. Rivadeneira, Imprenta de Atacama, Imprenta del Conservador (1857-1858), Imprenta del Deber (Valparaíso, 1850-1878), Imprenta del País (1857-1858), Imprenta del Siglo (1844-1848), Imprenta Elzeveriana, Imprenta Europea (Valparaíso, 1847-1865; Santiago, 1890-1914), Imprenta Gutenberg (1868-1877), Imprenta Franklin (1875-1913), Imprenta y Librería Ercilla (1892-1902), el impresor Pedro G. Ramírez (1884-1886), Imprenta Araucana (1835-1837, dirigida por M. Peregrino), Imprenta Calle Andrés Bello 2-A, Imprenta de El Correo del Sábado (La Serena, 1873).

La ley de 1834 consolida también el negocio de la imprenta y de los autores. Supongo que para algún editor o escritor debió ser importante advertir en el libro impreso su propiedad intelectual o su derecho de autor. La evidencia más antigua que he visto -con base en ediciones de 1818-1900 digitalizadas por la John Carter Brown Library y Memoria Chilena- está en las Correcciones lexigráficas sobre la lengua castellana en Chile, de Valentín Gormaz (Imprenta del Comercio, 1860), que consigna al reverso de la portada: "Esta obra es propiedad del autor y del editor, y todo ejemplar irá rubricado por ambos, sin cuyo requisito se considerará falsificado y se perseguirá conforme a la ley"..38 Este peritexto editorial de derecho de autor es de carácter formal y explicita tanto la propiedad y la relación contractual entre el editor y el autor como la persecución frente al delito y el procedimiento de autenticación del libro, ante posibles falsificaciones.

Dramas inéditos, de Salvador Sanfuentes (Imprenta Nacional, 1863), contiene un peritexto editorial que podríamos calificar de escueto, conciso, pues sólo marca la propiedad intelectual: "Es propiedad del Editor". ${ }^{39}$ Ese mismo

\footnotetext{
${ }_{38}$ Valentín Gormaz, Correcciones lexigráficas sobre la lengua castellana en Chile (Valparaíso: Imprenta del Comercio, 1860), 3.

${ }^{39}$ Salvador Sanfuentes, Dramas inéditos (Santiago: Imprenta Nacional, 1863), 2.
} 
año en el Tratado elemental de dibujo lineal, de Juan Bianchi, también de las prensas de la Imprenta Nacional y editado por la Librería de D. Pedro Yuste i Ca., aparece un peritexto editorial muy vinculado al espíritu de la edición de Valentín Gormaz, ya que destaca la persecución frente al delito y la manera de legitimar las copias: "Esta obra es propiedad del autor, quien perseguirá ante la ley cualquier fraude. Los ejemplares legítimos serán los que vayan numerados y rubricados por don Pedro Yuste". 40 Poetas chilenos (Imprenta de la Unión Americana, 1864), compilado por José Domingo Cortés, incluye un peritexto editorial neutral, pues únicamente habla de la propiedad intelectual: "Es propiedad del Editor". ${ }^{41}$ El libro Elementos de la lengua castellana arreglados segun el sistema de Swinton, de Fanor Velasco (Imprenta del Progreso, 1865), consigna que: "Es propiedad. Se ha depositado en la Biblioteca Nacional el número de ejemplares prescrito por la lei". ${ }^{42}$ Esta construcción literaria del peritexto editorial de derecho de autor explicita el procedimiento, sea de manera específica al mencionar el depósito de los ejemplares en la Biblioteca Nacional, sea vagamente al nombrar "los requisitos de la ley".

El libro Los estragos del tabaco (Imprenta del Independiente, 1867), menciona: "La presente es propiedad de su autor, habiéndose cumplido con los requisitos de la lei". ${ }^{43}$ Chile y su gobierno, de Martín Palma (Imprenta del Ferrocarril 1868), consigna: "Siendo este folleto una propiedad de su autor, suplica a los señores editores de los diarios que se sirvan no reproducirlo". ${ }^{44}$ En 1878, en las Relaciones históricas, de Benjamín Vicuña Mackenna, editado por Rafael Jover en la Imprenta de la Librería del Mercurio de E. Undurraga y Ca., aparece: "Esta obra es propiedad del editor, el cual no permitirá la reproducción o reimpresión de los artículos que la forman". ${ }^{45}$ Estos peritextos editoriales son importantes para el análisis y los hallazgos, pues además de declarar la propiedad, reafirman lo que no debe hacer el lector, la competencia, el otro; así, se establecen los usos prohibidos del objeto libro.

\footnotetext{
40 Juan Bianchi, Tratado elemental de dibujo lineal (Santiago: Librería de D. Pedro Yuste i Ca., 1863), 2.

${ }^{41}$ José Domingo Cortés, Poetas chilenos (Santiago: Imprenta de la Unión Americana, 1864), 3.

${ }^{42}$ Fanor Velasco, Elementos de la lengua castellana arreglados segun el sistema de Swinton (Santiago: Imprenta del Progreso, 1865), 5.

${ }_{43}$ Un ex-fumador, Los estragos del tabaco. O resultado de la esperiencia sobre el hábito de tragar el humo (Santiago: Imprenta del Independiente, 1867), 2.

${ }^{44}$ Martín Palma, Chile y su gobierno (Santiago: Imprenta del Ferrocarril, 1868), 2.

${ }^{45}$ Benjamín Vicuña Mackenna, Relaciones históricas (Santiago: Rafael Jover, editor, 1878), 2.
} 
La Historia verdadera de la Isla de Robinson Crusoe, de Benjamín Vicuña Mackenna, libro editado en 1833 por Rafael Jover en su Imprenta Cervantes, presenta el peritexto editorial muy escueto: "Es propiedad del editor". ${ }^{46}$ Por su parte, la Cañadilla de Santiago, de J. Abel Rosales (Establecimiento Tipográfico de La Época, 1887), tiene el siguiente peritexto editorial: "Esta obra es propiedad del autor. Queda hecho el depósito legal". ${ }^{47}$ En 1888, J. Abel Rosales publicó la Historia y tradiciones del puente Cal y Canto, editada por Manuel A. Mújica e impresa en la Imprenta Estrella de Chile, donde se consigna escuetamente: "es propiedad". ${ }^{48}$ El libro Poesías populares, de El Pequén (Imprenta de P. Ramírez, 1893), contiene el peritexto editorial de derecho de autor: "Esta publicación es propiedad de su editor, quien perseguirá ante la lei al que reimprimiere en todo o en parte". ${ }^{49}$ El gran crimen del Talca, de El Negro Peluca (Imprenta Calle Andrés Bello 2-A, 1894), consigna lo siguiente: "Propiedad del autor. Queda hecho el depósito que manda la lei".50

En el libro titulado Sara Bell o una víctima de la aristocracia, de Oscar HallPort (Centro Editorial, 1897), aparece lo siguiente: "Es propiedad, y habiendo hecho el depósito legal, se perseguirá judicialmente a quien reproduzca en todo o en parte esta novela en la República, sin permiso por escrito del autor y del editor". ${ }^{\prime 1}$ Y La joya literaria, de Juan R. González (Imprenta La Sin Rival, 1900), tiene este peritexto editorial de derecho de autor: "Es propiedad. Queda hecho el depósito que marca la lei. I se perseguirá a quien lo reimprima todo o en parte". ${ }^{22}$ De tal manera, el modelo de peritexto editorial que alude a la prohibición de ciertos usos del libro se caracteriza como la reproducción o reimpresión sin la autorización necesaria.

\footnotetext{
${ }^{46}$ Vicuña Mackenna, Historia verdadera de la Isla de Robinson Crusoe (Santiago: Rafael Jover, editor, 1883), 3.

47 J. Abel Rosales, Cañadilla de Santiago (Santiago: Establecimiento Tipográfico de La Época, 1887), 3. La frase "Esta obra es propiedad del autor. Queda hecho el depósito legal" es relevante porque distingue entre el objeto material (libro) y el inmaterial (obra), circunstancia que además denota que ambos constituyen un solo objeto de protección.

${ }^{48}$ Rosales, Historia y tradiciones del puente Cal y Canto (Santiago: Manuel A. Mújica, editor, 1888), 3.

${ }^{49}$ El Pequén, Poesías populares (Santiago: Imprenta de P. Ramírez, 1893), 2.

${ }^{50}$ El Negro Peluca, El gran crimen del Talca (Santiago: Imprenta Calle Andrés Bello 2-A, 1894), 6.

51 Oscar Hall-Port, Sara Bell o una víctima de la aristocracia (Santiago: Centro Editorial, 1897), 3.

52 Juan R. González, La joya literaria (Santiago: Imprenta La Sin Rival, 1900), 2.
} 
Dentro de esta historia literaria del derecho de autor en el siglo XIX es necesario destacar las historias de Josefina Mariscal y de los poetas de la Lira Popular. A finales de ese siglo podemos comprobar la presencia de, quizá, la primera editora chilena de libros. En la Historia Jeneral de Chile: tomo XIII, de Diego Barros Arana, editada por Rafael Jover (Imprenta Cervantes, 1894), aparece el peritexto editorial de derecho de autor: "Es propiedad del editor. Queda hecho el depósito exigido por la lei". ${ }^{53}$ Unos años después, en la Historia Jeneral de Chile: tomo XIV, del mismo Barros Arana, editada por Josefina M. v. de Jover (Imprenta Cervantes, 1897), se consigna: "Es propiedad de la editora. Queda hecho el depósito exigido por la lei". ${ }^{54}$ Estos últimos dos casos me parecen importantes de citar, pues Josefina Mariscal, con la muerte de Rafael Jover en 1896, sería la primera editora de libros en Chile, al continuar la edición de la Historia Jeneral de Chile..$^{55}$

El incipiente desarrollo del peritexto editorial de derecho de autor en la segunda mitad del siglo XIX está marcado por la presencia de los poetas de la Lira Popular. En las Poesías populares, de Nicasio García (Pedro G. Ramírez, 1886), aparece un peritexto editorial de derecho de autor, de carácter punitivo: "Esta obra es propiedad de su autor, quien perseguirá ante la lei al que la reimprimiere en todo o en parte", que se repite en la reimpresión de esa obra (Imprenta Estrella de Chile, 1892). ${ }^{56}$ Por su parte, el libro Poesías populares, de Rosa Araneda (Imprenta Cervantes, 1893), dice lo siguiente: "Se perseguirá por la lei a la persona que reimprima estas poesías sin permiso de su autora". ${ }^{57} \mathrm{Y}$ Daniel Meneses también usa el mismo peritexto editorial de derechos de autor en El cantor de los cantores (Imprenta Cervantes, 1895): "Se perseguirá por la lei a la persona que reimprima estas poesías sin permiso de su autor".58

${ }^{53}$ Diego Barros Arana, Historia Jeneral de Chile: tomo XIII (Santiago: Rafael Jover, editor, 1894), 3.

${ }^{54}$ Barros Arana, Historia Jeneral de Chile: tomo XIV (Santiago: Josefina M. v. de Jover, editora, 1897), 3.

${ }^{55} \mathrm{He}$ abordado brevemente la presencia de Josefina Mariscal en una nota para el Centro de Estudios Gráficos, "Josefina Mariscal de Palacios: la primera editora chilena de libros" (23 de enero de 2020), acceso el 21 de septiembre de 2020, https://www.centroestudios graficos.cl/post/josefina-mariscal-de-palacios-la-primera-editora-chilena-de-libros.

${ }_{56}$ Nicasio García, Poesías populares (Santiago: Pedro G. Ramírez, 1886), 2, y Poesías populares (Santiago: Imprenta Estrella de Chile, 1892), 2.

${ }^{57}$ Rosa Araneda, Poesías populares (Santiago: Imprenta Cervantes, 1893), 2.

${ }^{58}$ Daniel Meneses, El cantor de los cantores (Santiago: Imprenta Cervantes, 1895), 2. 
En la segunda mitad del siglo XIX, la impresión de libros ya no dependía necesariamente de la relación directa entre un autor y el impresor o la imprenta, pues comenzaron a aparecer los primeros editores, que financiaban la totalidad o una parte de la impresión. De acuerdo con los casos revisados, Rafael Jover es el primer impresor que se denomina editor, tal como apreciamos en las Relaciones históricas, de Benjamín Vicuña Mackenna, edición en la cual aparece "Rafael Jover, editor", publicada en 1877, si bien es factible que Jover haya marcado su nombre más su oficio en alguna edición más antigua. Después encontramos a Manuel A. Mújica, editor, consignado en las ediciones de Historias y tradiciones del puente Cal y Canto, y Sepulcros y difuntos, ambas de J. Abel Rosales (Imprenta Estrella de Chile, 1888). Eduardo Cadot aparece a finales del siglo XIX en el Atlas de Chile (1895), de Juan Türke, edición cuya portada consigna: "Eduardo Cadot, editor propietario". Un año después muere Rafael Jover y se hace cargo de la Imprenta Cervantes su esposa Josefina, quien se identifica en dos ediciones de la Historia Jeneral de Chile, de Diego Barros Arana, como Josefina M. v. de Jover, editora, y Josefina M. de Palacios, editora.

\section{Conclusiones}

Todos los casos citados permiten exponer algunas significativas conclusiones sobre este primer estadio en el paratexto de derechos exclusivos. Primero, se evidencia que existe doble concepción de propiedad sobre el objeto libro, pues sucede que la obra puede pertenecer tanto al autor como al editor, ya que se encuentra el peritexto editorial "es propiedad del editor" en una edición y el peritexto "es propiedad del autor" en otra. Pareciera que la propiedad material del libro podía pertenecer al editor o imprenta, o al autor, como sucedía en el caso de los poetas de la Lira Popular, quienes financiaban las ediciones de sus libros, por tanto, la propiedad literaria y material era de ellos. Sin embargo, es una incógnita el sentido de la diferencia entre la propiedad del editor y la del autor.

Segundo, es evidente que la ley no dispone la forma textual del peritexto editorial de derecho de autor, por eso es creación de los impresores y editores. La arbitrariedad textual del peritexto editorial de derecho de autor explica por qué se generaron distintas construcciones literarias, mientras que se replicaron ciertos peritextos en ediciones de otras imprentas. Le sucede, por ejemplo, a los peritextos "es propiedad del editor (o del autor)", "es propiedad del autor (o del editor). Queda hecho el depósito que exige la ley" y "esta obra es propiedad de 
su autor, quien perseguirá ante la ley al que la reimprimiere en todo o en parte", los cuales pueden apreciarse en distintas ediciones del periodo.

Es posible especular que la copia de las prácticas profesionales explica por qué existen recurrencias de paratextos de derechos exclusivos en libros de diferentes imprentas. Como el peritexto editorial de derecho de autor es un texto de carácter formal, es probable que las imprentas y los primeros editores (Rafael Jover, Josefina Mariscal, Guillermo Miranda, F. Becerra, Eduardo Cadot) valoraran y adoptaran en sus prácticas el quehacer del gremio de su tiempo: el chileno o mexicano. Además, el peritexto editorial de derecho de autor tiene un carácter formal y, en ocasiones, es neutral, escueto y conciso, o puede ser punitivo y prohibitivo; además, en el peritexto editorial de derecho de autor no hay humor, no todavía, supongo.

Tercero, es probable que durante la segunda mitad del siglo XIX, el uso del peritexto editorial de derecho de autor no haya sido una práctica recurrente en el diseño de las ediciones; por ejemplo, de la Imprenta Cervantes se revisaron 52 libros publicados desde 1883 hasta 1930, de los cuales 8 tienen peritexto editorial de derecho de autor. De la Imprenta, Litografía y Encuadernación Barcelona fueron revisadas 22 ediciones y hay 6 peritextos editoriales de derecho de autor. De la Imprenta Nacional, 38 ediciones, con una licencia estatal de impresión y un peritexto editorial de derecho de autor. De la Imprenta del Progreso se analizaron 13 ediciones y sólo hay un peritexto editorial de derecho de autor. De la Imprenta del Ferrocarril, 18 ediciones y un peritexto editorial de derecho de autor. Es factible pensar que este panorama de la impresión de libros entre 1830 y 1900 podría ser una tendencia en el resto de las imprentas.

Cuarto, si observamos la historia de la literatura chilena en esta etapa, se apreciará que luego de la publicación gubernamental y religiosa entre 1817 y 1828 , la publicación de los ilustrados chilenos y de los poetas populares (de la Lira Popular) marca la historia literaria del siglo XIX y, desde esta investigación, marca también el desarrollo del peritexto editorial de derecho de autor ya que, por un lado, la publicación sobre historia chilena de los primeros ilustrados chilenos era parcialmente financiada por impresores como Rafael Jover, que por ese acto de inversión comenzaron a usar el apelativo profesional de "editor", y gracias a ello el peritexto editorial de derechos de autor se nos muestra como una evidencia de la conciencia de aquellos editores-impresores e imprentas sobre la propiedad intelectual y el derecho de autor; por otro lado, el aporte de los poetas populares no sólo radica en el carácter prohibitivo del peritexto editorial usado por ese gremio de autores-editores, sino que también es un 
paratexto creado por un escritor: una temprana manifestación de la autopublicación y de la importancia de proteger los derechos patrimoniales de la propiedad intelectual.

Como ésta es una investigación en curso, hay preguntas importantes sobre el periodo que quedan abiertas, por ejemplo ¿cuál es el primer peritexto editorial de derecho de autor impreso en una edición chilena? El caso de 1860 no creo que sea el primero, sin embargo, es un punto de partida para una búsqueda futura -en la Biblioteca Nacional y en el Archivo Central Andrés Bello- del libro que contenga el primer peritexto editorial de derecho de autor. Asimismo, una búsqueda exhaustiva en los libros impresos entre 1810 y 1859 , y entre 1860 y 1900, permitirá encontrar no sólo más peritextos editoriales de derecho de autor, sino también casos de licencias católicas de impresión en las obras de temática religiosa, pues hay otros libros que quizá las contengan. Con lo anterior, es fundamental investigar también sobre la licencia estatal de impresión durante la primera y segunda independencias en Chile, labor que incluye un mayor corpus de impresos.

\section{Referencias}

Anónimo. Modo de ganar el Jubileo Santo. Santiago, 1776.

Araneda, Rosa. Poesías populares. Santiago: Imprenta Cervantes, 1893.

Ávila Martel, Alamiro de. El Modo de ganar el Jubileo Santo de 1776 y las imprentas de los incunables chilenos. Santiago: Imprenta Universitaria, 1976.

Barros Arana, Diego. Historia Jeneral de Chile: tomo XIII. Santiago: Rafael Jover, editor, 1894.

Barros Arana, Diego. Historia Jeneral de Chile: tomo XIV. Santiago: Josefina M. v. de Jover, editora, 1897.

Bianchi, Juan. Tratado elemental de dibujo lineal. Santiago: Librería de D. Pedro Yuste i Ca., 1863.

Biblioteca Nacional. Impresos chilenos 1776-1818. Vol. 1. Santiago: Biblioteca Nacional, 1963.

Cerda, Alberto. "Evolución histórica del Derecho de Autor en América Latina". Revista lus et Praxis 22, núm. 1 (2016): 19-58.

Constitución de la República de Chile jurada y promulgada el 25 de mayo de 1833. Santiago: Imprenta de La Opinión, 1833.

Constitución política del Estado de Chile. Santiago: Imprenta del Estado, 1822.

Constitución política del Estado de Chile. Santiago: Imprenta Nacional, 1823. 
Constitución política de la República de Chile. Santiago: Imprenta de R. Rengifo, 1828.

Cortés, José Domingo. Poetas chilenos. Santiago: Imprenta de la Unión Americana, 1864.

"Decreto del Gobierno con acuerdo del Senado sobre la libertad de la prensa". El Monitor Araucano, t. 1, núm. 35, 26 de junio de 1813.

Egaña, Juan. Cartas pehuenches, o correspondencia de dos indios naturales del Pire-Mapu, ó sea la quarta en Los Andes, el uno residente en Santiago, y el otro en las cordilleras pehuenches. Santiago: Imprenta de Gobierno, 1820.

Farías, Eduardo. "Josefina Mariscal de Palacios: la primera editora chilena de libros". Centro de Estudios Gráficos (23 de enero de 2020). Acceso el 21 de septiembre de 2020. https://www.centroestudiosgraficos.cl/post/jose fina-mariscal-de-palacios-la-primera-editora-chilena-de-libros.

García, Fernando. Demostracion teologica de la plena y omnimoda autoridad que por derecho divino y sin dependencia alguna del Papa tienen los obispos de sus respectivas diocesis. Santiago: Imprenta del Superior Gobierno, 1813.

García, Nicasio. Poesías populares. Santiago: Pedro G. Ramírez, 1886.

García, Nicasio. Poesías populares. Santiago: Imprenta Estrella de Chile, 1892.

García Cuadrado, Amparo. "Aproximación a los criterios legales en materia de imprenta durante la Edad Moderna en España". Revista General de Información y Documentación 6, núm. 2 (1996): 125-190.

Genette, Gérard. Umbrales. México: Siglo XXI Editores, 2001.

González, Juan R. La joya literaria. Santiago: Imprenta La Sin Rival, 1900.

Gormaz, Valentín. Correcciones lexigráficas sobre la lengua castellana en Chile. Valparaíso: Imprenta del Comercio, 1860.

Grajales, Manuel. Descripción de la verdadera, y falsa vacuna, y modo de ingerir el fluido vacuno, con los accidentes que acaecen antes y despues de su ingercion. Santiago: Imprenta Nacional, 1822.

Hall-Port, Oscar. Sara Bell o una víctima de la aristocracia. Santiago: Centro Editorial, 1897.

Ibarra Cifuentes, Patricio. "Liberalismo y prensa: Leyes de imprenta en el Chile decimonónico (1812-1872)". Revista de Estudios Históricos-Jurídicos, núm. 36 (2014): 293-313.

Laval, Ramón. Un incunable chileno. Modo de ganar el Jubileo Santo. Santiago: Imprenta Universitaria, 1910. 
Ley S/N, "Privilejio exclusivo", de 24 de julio de 1834. Ley Chile, Biblioteca del Congreso Nacional de Chile. Acceso el 21 de septiembre de 2020. https:// www.leychile. $c l / N ? i=1016800 \& f=1835-01-10 \& p=$.

Meneses, Daniel. El cantor de los cantores. Santiago: Imprenta Cervantes, 1895. Mirosevic, Camilo. "Origen y evolución del derecho de autor, con especial referencia al Derecho chileno". Revista de Derecho de la Pontifica Universidad Católica de Valparaíso 28, núm. 1 (2007): 35-82.

El Negro Peluca. El gran crimen del Talca. Santiago: Imprenta Calle Andrés Bello 2-A, 1894.

Palet, Andrea. "Brevísimo manual para jóvenes editores". El Malpensante, núm. 115 (diciembre de 2010). Acceso el 21 de septiembre de 2020. https:// www.elmalpensante.com/articulo/1734/brevisimo_manual_para_jove nes_editores.

Palma, Martín. Chile y su gobierno. Santiago: Imprenta del Ferrocarril, 1868.

El Pequén. Poesías populares. Santiago: Imprenta de P. Ramírez, 1893.

Proyecto de constitución provisoria para el Estado de Chile. Santiago: Imprenta del Gobierno, 1818.

Ramírez, Juan Ramón. La virjen de Andacollo. La Serena: Imprenta de El Correo del Sábado, 1873.

Reglamento constitucional provisorio del Pueblo de Chile. Santiago de Chile: Imprenta del Gobierno, 1812.

Reyes Gómez, Fermín de los. "El privilegio de los Diccionarios de Antonio de Nebrija (siglos XV-XVIII): otro enredijo de mil diablos". Corpus Eve. Émergence du Vernaculaire en Europe (2014): 1-26. https://doi.org/10.4000/eve.850.

Rosales, J. Abel. Cañadilla de Santiago. Santiago: Establecimiento Tipográfico de La Época, 1887.

Rosales, J. Abel. Historia y tradiciones del puente Cal y Canto. Santiago: Manuel A. Mújica, editor, 1888.

Sanfuentes, Salvador. Dramas inéditos. Santiago: Imprenta Nacional, 1863.

Soto Veragua, Jorge. La historia de la imprenta, desde el siglo XVIII hasta el XXI. Santiago: El Árbol Azul, 2009.

Subercaseaux, Bernardo. Historia del libro en Chile. Desde la Colonia hasta el Bicentenario. Santiago: LOM Ediciones, 2010.

Torre Revello, José. El libro, la imprenta y el periodismo en América durante la dominación española. Edición facsimilar. México: Universidad Nacional Autónoma de México, Instituto de Investigaciones Bibliográficas, 1991. 
Un ex-fumador. Los estragos del tabaco. O resultado de la esperiencia sobre el hábito de tragar el humo. Santiago: Imprenta del Independiente, 1867.

Una religiosa capuchina. Convento Espiritual. Santiago: José Camilo Gallardo, impresor, 1813.

Velasco, Fanor. Elementos de la lengua castellana arreglados segun el sistema de Swinton. Santiago: Imprenta del Progreso, 1865.

Vicuña Mackenna, Benjamín. Historia verdadera de la Isla de Robinson Crusoe. Santiago: Rafael Jover, editor, 1883.

Vicuña Mackenna, Benjamín. Relaciones históricas. Santiago: Rafael Jover, editor, 1878.

Zúñiga Saldaña, Marcela. "Privilegios para imprimir libro en la Nueva España, 1714-1803. La renta de un monopolio editorial". Estudios del Hombre, núm. 20 (2005): 59-86. Acceso el 21 de septiembre de 2020. http://148.202.18.157/sitios/publicacionesite/pperiod/esthom/esthomp df/esthom20/59-86.pdf. 